\title{
GRAMMAR, USAGE, OR STYLE? RULE VIOLATIONS IN STUDENT WRITING
}

\author{
LAURel J. Brinton
}

\section{INTRODUCTION}

Student writers may make, as we all know, a variety of sentence-level mistakes, which differ in their seriousness and in their fundamental character. However, there is a failure in handbooks on technical writing-and on writing generally--and among teachers of writing to distinguish among such errors: all are accorded the same degree of seriousness. In fact, we tend to concentrate on lower-level errors, because these can be treated in a more facile fashion, and we are even tempted to portray such errors as more serious than they actually are. The situation described here stems, I believe, from our not differentiating between violations of those rules which are purely regulatory, or 'stylistic', and those which are constitutive, or 'grammatical'; both sets of rules are frequently treated in handbooks under the ambiguous rubrics of 'usage' or 'mechanics'. The purpose of this paper is to point out the differences among rules of grammar, rules of usage, and rules of style and the significance of these differences for the teaching of technical writing; to survey the treatments of these rules in a number of technical writing textbooks; and to provide a preliminary classification of student errors on the basis of this three-way classification.

\section{THE DISTINCTION AMONG RULES OF GRAMMAR, RULES OF STYLE, AND RULES OF USAGE}

\section{Definitions of grammar, usage, and style}

There is a long history of overlap among the terms grammar, usage, and style. Among other confusions, grammar is often conflated in a prescriptive sense with usage, and the concept of usage is understood broadly to cover matters of grammar and style as well as those of usage. Nonetheless, I believe that it is possible to distinguish these three notions. Grammar, here used in its descriptive sense, refers to the intrinsic system of rules by which a language operates; usage refers to the forms of language which are habitually or standardly used, especially in cases where muitiple 
forms exist; and style, by one of the most widely accepted definitions, refers to the choice of one particular means of expression rather than another. An example of a rule of grammar would be that subject-verb agreement in English requires a present tense $-s$ ending on the verb with a 3rd person singular subject (John walks the dog); a dictum of usage would be that with a disjunctive or correlative subject, the verb agrees with the closer subject (Either the boys or Mary walks the dog); and a rule of style would be that parallel structure is preferred (John says that he likes walking the dog and taking out the trash).

\section{Distinguishing among rules of prammar, usage, and style}

There are a number of ways in which grammar, usage, and style can be differentiated. First, usage and style, but not grammar, involve value judgments: a particular usage or style may be deemed 'good' or 'bad', 'correct' or 'incorrect', 'standard' or 'non-standard', 'preferred' or 'not preferred'. That is, rules of usage and style are prescriptive rather than descriptive. Second, violations of the three kinds of rules have very different consequences. Violations of rules of grammar yield ungrammatical sentences, which no speaker of English would accept as grammatically acceptable (e.g. John walk the dog). Violations of rules of usage yield non-standard, informal, colloquial, dialectal, or perhaps ungrammatical sentences (e.g. Either the boys or Many walk the dog). And violations of rules of style yield sentences which would be considered stylistically awkward or inelegant, rhetorically ineffective, or unclear (John says that he likes to walk the dog and taking out the trash). In a strict sense, rules of usage and style are, then, not rules at all, since they merely regulate rather than constitute linguistic behavior.

Third, the three types of rules have entered the language at different times and by different means. The rules of grammar have, one might say, always been with us, though they have, of course, undergone change as the language has changed. In contrast, many (if not all) rules of usage entered English in the 18th century, in the flourishing of prescriptive traditional grammar. The regulatory rules devised in the 18 th century were based most frequently on the model of Latin grammar (for example, rules concerning case usage) and upon rules of logic and reason (for example, rules concerning the placement of modifiers or the use of double negatives). Many rules of style also originated in 18th century notions of order and decorum in language, though literary styles have, naturally, undergone change in the last two centuries. 


\section{Factors which obscure the distinction}

A number of factors-both in handbooks and in the writing class-serve to obscure the distinction among rules of grammar, usage, and style. Congregation of all sentence-level errors under the uninformative label of 'usage', understood in its broadest sense, obscures the distinction, and, as I will suggest later, alternative arrangements and classifications of sentencelevel mistakes can be equally misleading or flawed, as are the discussions of the errors themselves. Alphabetic listings in handbooks of sentence-level errors or of correction symbols might likewise suggest the equivalence of the different kinds of mistakes. The correction symbols themselves are frequently inadequate or even ambiguous; for example, the symbol ww for 'wrong word' may indicate a word which is denotatively wrong (hence a violation of a rule of grammar), standardly, registrally, or dialectally wrong (hence a violation of a rule of usage), or connotatively or stylistically wrong (hence a violation of a rule of style). Finally, when we comment at the end of a student's paper about 'errors of expression' or 'mechanical mistakes', and include among such errors ones of grammar, usage, style and even punctuation, we are probably also doing the student a disservice.

\section{Significance of the distinction for the teaching of technical writing}

The distinction among these different types of rules has special significance for the teaching of technical writing as opposed to general composition, for a basic proficiency is generally assumed in technical writing handbooks. As teachers of technical writing, we are not perforce required to deal with serious grammatical problems in our students' writing, but may concentrate on more sophisticated matters of style and usage. Most technical writing textbooks recognize this reality: a chapter on style is placed within the text, while a chapter (or 'handbook') on grammar and usage is relegated to an appendix. But the attempts at distinguishing these different concerns are not always entirely successful. The appendices are often a conglomeration of rules of grammar, usage, and style, as well as of punctuation and mechanics, with no attempt to differentiate the various areas, while the chapters on style within the texts are normally confined to matters of clarity and conciseness, suggesting that these are the bounds of style. 


\section{TREATMENT OF GRAMMAR, USAGE, AND STYLE IN TECHNICAL WRITING TEXTBOOKS}

I have examined the treatment of rules of grammar, usage, and style in a representative sample of technical writing handbooks and found, as one would expect, that none is wholeheartedly wrong in its classification of the various types of rules, but that each contains some problems or confusions of classification. (Full bibliographical information of the six textbooks referred to in the following discussion is appended.)

\section{Problems of classification in representative technical writing textbooks}

With one exception (Pauley and Riordan), all of the books surveyed contain a chapter on style within the text, and all place discussions of grammar and usage either as the last section of the text or as an appendix; two (Houp and Pearsall, Lannon) give lists of correction symbols crossreferenced to discussions in the text or appendix. While I was not always in agreement with the stylistic recommendations, I found that the chapters on style were, for the most part, properly restricted to matters of style; however, I discovered that the handbooks were generally a rather confusing mixture of rules of style, grammar, usage, and mechanics.

Chapter on style. In the chapters on style, there is not only unanimity on those aspects of style important in technical writing, that is, clarity, accuracy, precision, and conciseness, or what is described by several as 'readable' style, but nearly a consensus on the forms and constructions which contribute to such a style. All the textbooks caution students about diction which is abstract, imprecise, vague, empty, trite, pompous, euphemistic, unfamiliar, or sexist and about the use of jargon; all likewise advise students about sentence structure, addressing matters of length, complexity, density, order of elements, and variety. Four books (Andrews and Blickle, Houp and Pearsall, Lannon, Sherman and Johnson) recommend the use of the active rather than the passive voice (interestingly, this is considered a matter of 'clarity'), and four (Andrews and Blickle, Lannon, Mills and Walter, Sherman and Johnson) argue for conciseness, warning against wordiness, repetition, and needless words and phrases. Some attention is also focused on nouns and verbs: three textbooks (Andrews and Blickle, Houp and Pearsall, Lannon) suggest that students use strong, 'active' verbs rather than 'weak' or 'smothered' verbs, and two books (Houp and Pearsall, Lannon) caution against 'noun strings', 'stacked noun modifiers', or 'noun addiction'.

The chapters on style in the textbooks are, for the most part, 
restricted to matters of style and only occasionally address matters of grammar and usage. Two points of usage, namely, the placement of modifiers (Andrews and Blickle, Mills and Walter) and levels of formality (Andrews and Blickle, Sherman and Johnson), arise twice, and a number of grammatical points appear sporadically: ambiguity, redundancy, denotation, basic word order, sentence types, predication, and parts of speech. At times, however, the discussion of these grammatical points provides necessary background for the stylistic issues raised.

Handbook on grammar and usage. In the textbooks examined, the handbooks are divided into either two or three sections. A basic division is made between matters of grammar and usage, treated under a rubric such as 'common sentence errors', and matters of punctuation and mechanics, treated under a rubric such as 'conventions'. A third division, found in two of the textbooks, contains a glossary of usage or of 'frequently misused words'.

In all of the textbooks, the sections on sentence errors freely mix questions of usage and grammar; I will not detail the extent of the mixture here. Several of the textbooks remark upon the variability and arbitrariness of usage: Andrews and Blickle note that 'principles of usage come into and go out of fashion' (403), while Sherman and Johnson observe that there is often disagreement 'about whether some form may be used' and claim that their view on matters of usage is 'liberal' (415). Mills and Walter likewise take a liberal stance, claiming not to be giving prescriptions but rather to be recording 'the observed practices of successful writers and speakers' (462). Sherman and Johnson make a subdivision between 'Standard Usage' and 'Unity and Coherence in the Sentence'; the former is correctly restricted to fine points of agreement, case usage, and differentiation of forms--all clearly points of usage, not grammar-but the latter unfortunately includes matters of usage as well as of grammar and style.

More significant than the conflation of grammar and usage is the inclusion of many rules of style in the handbooks, with little or no indication of the optional nature of these rules. Violations of stylistic rules which are discussed as 'sentence errors' in more than one of the handbooks include the following: lack of parallel structure; shifts in tense, mood, person, or number; vague pronoun reference; overuse of expletives; misuse of the passive; faulty diction; choppy sentences; problems of coordination and subordination; and misuse or lack of connectives.

In all of the handbooks, the second sections deal quite straightforwardly with questions of punctuation, abbreviation, capitalization, 
spelling, numerals, symbols, and hyphenation. These are rightly recognized in three of the texts (Andrews and Blickle, Houp and Pearsall, Mills and Walter) as matters of 'convention' or 'usage'. However, the mistake of 'comma splice' is invariably treated in the first section as a sentence error, a problem of sentence construction or unity. Sherman and Johnson articulate the assumption underlying this treatment: 'It [comma splice] is more than a mere mistake in punctuation; it is a serious error in sentence structure--an indication that the writer does not know when a statement is complete' (427). ${ }^{1}$

Serious confusions occur in the third sections, the glossaries of usage, found in Andrews and Blickle and in Sherman and Johnson. (Mills and Walter include a short glossary of usage in their chapter on style.) I will use the glossary in Sherman and Johnson as an example. It discusses real differences between words (affect vs. effect), correct inflectional forms (come vs. came), problems of case usage (who vs. whom) and other kinds of usage (because vs. for), redundancies (seldom ever), and egregious mistakes (of for have) and gives quite a number of stylistic proscriptions (against the use of hopefully, and/or, as per, and with as a vague connective). Though it notes that certain forms are merely 'undesirable', 'informal', 'colloquial', or 'dialectal' rather than clearly 'wrong', it at the same time lists the preferred form as 'correct'.

\section{Consequences for the teaching of writing}

The failure to distinguish rules of grammar, rules of usage, and rules of style has consequences for both instructors and students. When instructors do not distinguish subjective judgments about style from objective judgments of grammatical correctness and from more or less objective judgments about standard usage, they suggest to students that all errors are of the same nature and importance, whether they result from inattention to aesthetic concerns or to the needs of the audience, from gaps in grammatical competence, or from lack of awareness of or confusion about certain linguistic conventions. Students may become discouraged about the number of errors that they are making, when many are not 'errors' at all but stylistic preferences; they may feel that they are not improving in their writing, when in fact they have eliminated serious grammatical and usage errors and now need only improve their style; or they may decide that all aspects of writing are thoroughly arbitrary and subjective. Furthermore, when instructors treat the rules of punctuation as surface manifestations of rules of grammar, they suggest to students that punctuation is somehow 'natural' and invariable. In doing so, they both overplay the importance of punctuation and underestimate the student, who is assumed to be grammatically incompetent 
rather than, as is usually the case, merely ignorant of the proper conventions. ${ }^{2}$ Students may begin to believe that correct punctuation is more important than, or productive of, correct sentence structure.

\section{A PRELIMINARY CLASSIFICATION OF ERRORS}

Although I do not wish to suggest that the divisions among rules of grammar, usage, and style are absolutely clear and certain, I do believe that the distinction is both useful and valid. As a preliminary classification (see Table 1), I have sorted out the errors most frequently recorded in handbooks into three categories based on the types of sentences which result: ungrammatical (containing a violation of a rule of grammar); non-standard (containing a violation of a rule of usage); and awkward (containing a violation of a rule of style). The seriousness of the errors decreases from the left to the right column, that is, from fairly extensive to rather minimal impairment of meaning. Within each column, however, there is a range of seriousness which I have not attempted to indicate; for example, some errors affect form alone (e.g. wrong verb form), whereas others affect both meaning and form (e.g. predication). The latter are obviously more serious.

Although I do not have space to comment on this classification in detail, I wish to make a few observations. First, errors may appear in more than one category. For example, while subject-verb agreement is a basic feature of English grammar, some finer points of agreement, such as in cases of collective nouns, indefinites, or correlatives as subjects, usage was fixed quite late (in the 18th century) or is still variable in dialects of standard Modern English. On the other hand, 'usage' (especially as it is used in 'glossary of usage') is an ambiguous term referring to real lexical differences (e.g. imply vs. infer, compliment vs. complement), or to differences in usage, often quite arbitrarily established in the 18th century (e.g. among vs. between, farther vs. further, shall vs. will), or to mere stylistic preferences (e.g. proscriptions against hopefully, utilize, factor). Second, errors may, over time, change categories. Most of us would agree, I think, that splitting infinitives or ending sentences with prepositions, which for the 18th century grammarians violated rules of logic, or that failure to use subjunctive forms, which worked against the analogy of Latin, have now become rather minor stylistic lapses rather than examples of non-standard usage. In contrast, the distinction between adjectival and adverbial forms, established by the 18th century grammarians based on rules of reason, as well as matters of case usage, based on the model of Latin, have become so fully accepted into the language that they might be reclassified as rules of grammar; however, the fact that standard spoken English shows significant differences from written 
English in respect to case usage (i.e. in the use of whom) militates against such a reclassification.

I have not included mistakes of punctuation and of mechanics in Table 1. For the most part, these (e.g. errors in end punctuation, the use of commas, semi-colons, colons, and apostrophes, spelling, capitalization, and hyphenation) are matters of convention or usage, and thus belong in the second column. However, some (e.g. errors in the use of quotation marks, italics, abbreviations, numerals, dashes, parentheses, brackets, or exclamation points) may depend upon the style, for example, formality, of the document or the 'style sheet' followed, and thus belong in the third column.

\section{CONCLUSION}

As teachers of technical writing (and as potential writers of technical writing textbooks), I think that it is important that we be aware of the differences among the three kinds of rules, and especially of the different consequences of violating the rules, and that we make these differences clear to our students. We must additionally beware of the automatic or mechanical marking of errors on student papers. While violations of grammatical rules should, of course, always be marked, special restraint should be used in making stylistic corrections; mistakes of usage should be marked only with full cognizance of the variable and changing nature of usage, even in standard written English. 
TABLE 1

Classification of sentence errors

Ungrammatical Non-standard Awkward

faulty syntax

predication error

mixed construction

run-on sentence

fragment

faulty subj.-verb agreement

faulty pro.-antec. agreement

article error

wrong form of verb/noun

sequence of tenses

ambiguous pro. reference

squinting modifier

redundancy

no such word

wrong word ( $=$ some usage) case usage

use of subjunctive

comp. vs. superlative

verb + prep. idiom

improper comparison

some subj.-verb agreement

some pro.-antec. agreement

some article usage

adverb vs. adjective

place of preposition

split infinitive

misplaced modifier

dangling modifier

double negative

some usage improper subordination or coordination

choppy sentences overly long sentences incomplete comparison passive

stacked nouns

expletives

repetition, wordiness

diction error

vague pro. reference

shifts in tense, mood,

or voice

multiple negatives

some usage

\section{NOTES}

${ }^{1}$ It is not clear to me why comma splice, among all possible punctuation errors, is accorded this special treatment. One could equally well argue, for example, that misuse of the apostrophe indicates that a writer cannot distinguish possessive from non-possessive or even plural from possessive. And a similar line of reasoning could be constructed for each of the other marks of punctuation to show that its misuse is not 'a mere mistake in punctuation'.

${ }^{2}$ While any mistake in punctuation could conceivably be a violation of a grammatical rule (see n. 1), I believe that students should be assumed innocent until proven guilty. That is, they should not be thought to have violated a grammatical rule until evidence other than that from punctuation can be found. A comma splice may result solely from misunderstanding about the use of a comma, not from the inability to recognize a clause. 


\section{TECHNICAL WRITING TEXTBOOKS CITED}

Andrews, Deborah C. and Margaret D. Blickle. Technical Writing: Principles and Forms. 2nd ed. New York: Macmillan, 1982.

Houp, Kenneth W. and Thomas E. Pearsall. Reporting Technical Information. 6th ed. New York: Macmillan, 1988.

Lannon, John M. Technical Writing. 4th ed. Boston \& Toronto: Little, Brown, and Company, 1988.

Mills, Gordon H. and John A Walter. Technical Writing. With the assistance of Vody Mills and Marion K. Smith. 5th ed. New York: Holt, Rinehart and Winston, 1986.

Pauley, Steven E. and Daniel G. Riordan. Technical Report Writing Today. 3rd ed. Boston: Houghton Mifflin, 1987.

Sherman, Theodore A. and Simon S. Johnson. Modem Technical Writing. 4th ed. Englewood Cliffs, NJ: Prentice Hall, 1983.

Laurel J. Brinton is a member of the Department of English, University of British Columbia. 